\title{
Stability of the Homopentameric B Subunits of Shiga Toxins 1 and 2 in Solution and the Gas Phase as Revealed by Nanoelectrospray Fourier Transform Ion Cyclotron Resonance Mass Spectrometry
}

\author{
Elena N. Kitova and Rambod Daneshfar \\ Department of Chemistry, University of Alberta, Edmonton, Alberta, Canada \\ Paola Marcato \\ Department of Microbiology and Immunology, Dalhousie University, Halifax, Nova Scotia, Canada \\ George L. Mulvey and Glen Armstrong \\ Department of Microbiology and Infectious Diseases, Faculty of Medicine, University of Calgary, Alberta, \\ Canada
}

John S. Klassen

Department of Chemistry, University of Alberta, Edmonton, Alberta, Canada

\begin{abstract}
The assembly of the B subunits of Shiga toxins (Stx) 1 and 2 and the influence of solution conditions (protein concentration, temperature, $\mathrm{pH}$, and ionic strength) on it are investigated using temperature-controlled nanoflow electrospray (nano-ES) ionization and Fourier-transform ion cyclotron resonance mass spectrometry. Despite the similar higher order structure predicted by $\mathrm{X}$-ray crystallography analysis, the $B_{5}$ homopentamers of Stx1 and Stx2 exhibit differences in stability under the solution conditions investigated. At solution temperatures ranging from 0 to $60{ }^{\circ} \mathrm{C}$ and subunit concentrations ranging from 5 to $85 \mu \mathrm{M}$, the Stx1 B subunit exists almost entirely as the homopentamer in aqueous solutions, independent of the ionic strength. In contrast, the degree of assembly of Stx 2 B subunit is strongly dependent on temperature, subunit concentration, and ionic strength. At subunit concentrations of more than $50 \mu \mathrm{M}$, the Stx2 B subunit exists predominantly as a pentamer, although smaller multimers (dimer, trimer, and tetramer) are also evident. At lower concentrations, the Stx 2 B subunit exists predominantly as monomer and dimer. The relative abundance of multimeric species of the Stx2 B subunit was insensitive to the ion source conditions, suggesting that gas-phase dissociation of the pentamer ions in the source does not influence the mass spectrum. Blackbody infrared radiative dissociation of the protonated $B_{5}$ ions of Stx 2 at the +12 and +13 charge states proceeds, at reaction temperatures of 120 to $180{ }^{\circ} \mathrm{C}$, predominantly by the ejection of a single subunit from the complex. Dissociation into dimer and trimer ions constitutes a minor pathway. It follows that the dimer and trimer ions and, likely, the monomer ions observed in the nano-ES mass spectra of Stx2 B subunit originated in solution and not from gas-phase reactions. It is concluded that, under the solution conditions investigated, the homopentamer of Stx2 B subunit is thermodynamically less stable than that of Stx1 B subunit. Arrhenius activation parameters determined for the protonated Stx $2 B_{5}$ ions at the +12 and +13 charge states were compared with values reported for the corresponding $B_{5}$ ions of Stx 1 B subunit. In contrast to the differential stability of the Stx1 and Stx2 B pentamers in solution, the dissociation activation energies $\left(E_{\mathrm{a}}\right)$ determined for the gaseous complexes are indistinguishable at a given charge state. The similarity in the $E_{\mathrm{a}}$ values suggests that the protonated pentamer ions of both toxins are stabilized by similar intersubunit interactions in the gas phase, a result that is in agreement with the X-ray crystal structures of the holotoxins. (J Am Soc Mass Spectrom 2005, 16, 1957-1968) (C) 2005 American Society for Mass Spectrometry
\end{abstract}

Published online October 20, 2005

Address reprint requests to Dr. J. S. Klassen, Department of Chemistry, University of Alberta, Edmonton, Alberta, Canada, T6G 2G2. E-mail: john.klassen@ualberta.ca
$\mathrm{T}$ The Shiga toxins (Stx's) 1 and 2 are bacterial enterotoxins produced by the enterohemorrhagic group of enterovirulant Escherichia coli (EHEC) [1]. These organisms represent a subgroup of the Shiga toxigenic E. coli and are isolated from human subjects experiencing hemorrhagic colitis and, occasionally, he- 
molytic-uremic syndrome (HUS). Although numerous EHEC serotypes have been isolated from subjects experiencing hemorrhagic colitis, E. coli O157:H7 represents the predominant serotype in North America, Japan, and Europe. EHEC infection most commonly occurs from the consumption of contaminated undercooked ground beef, unprocessed contaminated drinking water, or other products that have been exposed to a source of contaminated unprocessed water [1].

The clinical signs associated with hemorrhagic colitis are mainly due to the ability of EHEC to colonize human gastrointestinal epithelial cells by a characteristic attaching and effacing mechanism involving numerous virulence-associated factors [2]. Stx1 and Stx2 also contribute to the hemorrhagic colitis phase of the illness by exacerbating the host inflammatory response to the infection. In $\sim 10-15 \%$ of subjects, mostly young children and the elderly, EHEC infections can progress to HUS, which may be life threatening. HUS occurs when the Stx's spread systemically throughout the body and attack endothelial cells, predominantly those forming the glomerular capillaries in the kidney [1]. This precipitates a cascade of pathological events leading to a decline in circulating platelets (thrombocytopenia), hemolytic anemia, and acute renal failure. In very severe cases, blood vessels nourishing the central nervous system also can be effected and this results in neurological complications as well as the renal involvement.

The Stx's display classical $\mathrm{AB}_{5}$ structures, in which a single A subunit ( $32 \mathrm{kDa}$ ) is associated with five identical B subunits $(8 \mathrm{kDa})[3,4]$. The A subunit is responsible for toxicity and acts by shutting down protein biosynthesis in target cells. The five B subunits assemble into a doughnut-shaped structure in which the central pore created by the $B$ subunits hosts the $C$ terminus of the $A$ subunit $[3,4]$. The $B_{5}$ homopentamers contain multiple binding sites for a glycolipid (Gal $\alpha 1$ $4 \mathrm{Gal} \beta 1$-4glucosyl-ceramide, Gb3), the natural cell surface receptor that is located on the surface of target cells [5].

The amino acid sequences of the A and B subunits of Stx 1 and Stx 2 are 52 and $60 \%$ homologous, respectively $[6,7]$. The theoretical isoelectric point ( $\mathrm{pI})$ values of Stx1 and Stx2, calculated from their amino acid sequences, are 6.5 and 5.2, respectively. The $\mathrm{pI}$ values for the $\mathrm{A}$ subunits are 8.7 (Stx1) and 8.0 (Stx2) and for the B subunits the values are 5.6 (Stx1) and 4.7 (Stx2). Both toxins possess similar numbers of basic (Stx1 A subunit: $24 \times$ Arg, $3 \times$ Lys, $8 \times$ His; Stx 1 B subunit: $2 \times$ Arg, $6 \times$ Lys, 1 x His; Stx2 A subunit: 24 x Arg, 3 x Lys, 7 x His; Stx2 B subunit: $1 \times$ Arg, $6 \times$ Lys) and acidic residues (Stx1 A subunit: $18 \times$ Asp, 7 x Glu; Stx1 B subunit: 5 x Asp, 3 x Glu; Stx2 A subunit: 11 x Asp, 15 x Glu; Stx2 B subunit: $5 \times$ Asp, $5 \times$ Glu). X-ray crystal structures of both the Stx1 and the Stx2 holotoxins and the Stx1 $B_{5}$ homopentamer complexed with the $\mathrm{P}^{\mathrm{k}}$ trisaccharide, a structural analog of the carbohydrate component of Gb3, have been solved [3-5, 8]. A comparative analysis of the two holotoxin structures reveals that the B subunits of both toxins exhibit similar secondary, ter- tiary, and quaternary structure. Each subunit within the homopentamer forms two three-stranded antiparallel $\beta$-sheets and an $\alpha$-helix. The second $\beta$-strand of each B subunit monomer interacts with the sixth $\beta$-strand of the neighboring monomer. Putative intersubunit interactions were identified from the X-ray crystal structures for Stx1 and Stx2. In this analysis, each of the neighboring pairs of subunits can form two intersubunit hydrogen bonds (Tyr14-Asn35 and Phe68-Thr12); three salt bridges were identified for the Stx 1 B subunit (Glu10-Arg69, Glu65-Lys13, and Arg33-Asp18) and two for the Stx2 B subunit (Glu64-Lys12 and Arg32-Asp17). The tertiary structure of each subunit is also stabilized by a disulfide bond between two Cys amino acids located in the first and the fifth $\beta$-strands. As well, the quaternary structure of the pentamer is likely stabilized by hydrophobic interactions between the $\alpha$-helices that line the pore of the complex. A solution structure obtained by NMR also has been reported for the Stx $1 B_{5}$ homopentamer [9] and found to be in agreement with $X$-ray data. To our knowledge, the structure and stability of Stx 2 or the Stx $2 B_{5}$ homopentamer in solution have not been previously investigated.

Despite their similar crystal structures $[3,4]$ and sequences [6,7], the two Stx exhibit differences in biological activity, with Stx2 being more potent than Stx1 in vitro and in vivo and more closely associated with the most severe consequences of $E$. coli infections in humans [10-17]. The origin of the differential toxicities of Stx1 and Stx2 is not fully known but may arise from differences in receptor recognition or differences in the structure and stability of the Stx B subunits [18], which are not apparent in the X-ray crystal structures.

The assembly of Stx1 and the Stx1 B pentamers in aqueous solution has been previously studied by nanoelectrospray mass spectrometry (nano-ES/MS) [19]. It was shown that the $B_{5}$ homopentamer of the Stx1 B subunit is readily observed in spectra produced from aqueous solutions with a $\mathrm{pH}$ of 3.5-7. The intact holotoxin was also observed, albeit from an acidified solution ( $\mathrm{pH}$ 3.5). Mass spectrometry has not previously been used to investigate the assembly of Stx2 or the Stx2 B pentamer. In the present work we have applied temperature-controlled nano-ES and Fourier-transform ion cyclotron resonance mass spectrometry (FT-ICR/ MS) to compare the influence of solution conditions (concentration, temperature, $\mathrm{pH}$, and ionic strength) on the assembly of the B subunits of Stx1 and Stx2. The main objective was to assess the relative stabilities of the two homopentamers under the different solution conditions investigated. In addition, time-resolved thermal dissociation experiments, implemented with the blackbody infrared radiative dissociation (BIRD) technique $[20,21]$, were used to assess the dissociation pathways, kinetics, and energetics of the protonated $B_{5}$ ions of Stx2 in the gas phase. These data were then compared with results obtained previously for the corresponding Stx1 ions [22] to establish the relative stabilities of the 
pentamer ions in the gas phase. The solution and gas-phase measurements allow a comparison of the relative thermal stabilities of structurally related protein complexes in solution and in the gas phase.

\section{Materials and Methods}

\section{Proteins}

Stx1 B and Stx2 B were expressed in E. coli using a procedure described previously [23]. Both proteins were purified to more than $95 \%$ purity by affinity chromatography, as described in one of our previous articles [24]; dialyzed against 50 or $100 \mathrm{mM}$ of ammonium acetate $(\mathrm{pH} 7)$; and stored at $-20{ }^{\circ} \mathrm{C}$. A stock solution of the Stx1 B subunit at a concentration 1.15 $\mathrm{mg} / \mathrm{mL}(150 \mu \mathrm{M})$ in $50 \mathrm{mM}$ of ammonium acetate and three stock solutions of the Stx2 B subunit, at concentrations of $1 \mathrm{mg} / \mathrm{mL}(130 \mu \mathrm{M}$, Stock 1) in $50 \mathrm{mM}$ of ammonium acetate $(\mathrm{pH} \mathrm{7})$, and $4.3 \mathrm{mg} / \mathrm{mL}(550 \mu \mathrm{M}$, Stock 2) and $1.5 \mathrm{mg} / \mathrm{mL}(190 \mu \mathrm{M}$, Stock 3$)$ in $100 \mathrm{mM}$ of ammonium acetate ( $\mathrm{pH} 7)$ were prepared. The nano-ES solutions were prepared by thawing the stock solutions at room temperature and diluting an aliquot to a concentration of between 5 and $85 \mu \mathrm{M}$ with aqueous ammonium acetate. The stock solutions were subjected to several freeze-thaw cycles without any observable influence on binding in solution. Unless otherwise specified, all of the nano-ES solutions were allowed to stand for at least 10 min before acquiring mass spectra to establish an equilibrium distribution of the different oligomeric states of the B subunits.

\section{Mass Spectrometry}

All experimental measurements were performed using a modified Apex II 4.7-tesla FT-ICR/MS (Bruker, Billerica, MA) equipped with a temperature-controlled nano-ES device developed in our laboratory [25]. The nano-ES device consists of a Plexiglass chamber that surrounds the sampling capillary of the ion source. The chamber is lined with a copper sleeve that is in thermal contact with copper tubing that can be regulated to temperatures ranging from 0 to $60{ }^{\circ} \mathrm{C}$ by circulating heated or cooled air. A portion of the circulating air is also introduced directly into the chamber to satisfy the air intake requirement of the ion source. Using this dual approach, the temperature inside the chamber can be regulated to within $\pm 1.5{ }^{\circ} \mathrm{C}$. Nano-ES tips, with an outer diameter (o.d.) of 4-7 $\mu \mathrm{m}$, were pulled from aluminosilicate tubes (1-mm o.d. and $0.68-\mathrm{mm}$ inner diameter [i.d.]) using a P-2000 micropipette puller (Sutter Instruments, Novato, CA). A platinum wire, inserted into the other end of the nano-ES tip, was used to establish electrical contact with the nano-ES solution. A potential of $\pm 600-800 \mathrm{~V}$ was applied to the platinum wire in the nano-ES tip to spray the solution. The tip was positioned 1-2 $\mathrm{mm}$ from a stainless steel sampling capillary using a microelectrode holder. Typical solu- tion flow rates were $20-50 \mathrm{~nL} / \mathrm{min}$, depending on the o.d. of the nano-ES tip and the voltage used. Charged droplets and solvated ions emitted by the nano-ES tip were introduced into the vacuum chamber of the mass spectrometer through a heated stainless steel sampling capillary $(0.43-\mathrm{mm}$ i.d.) maintained at an external temperature of $66^{\circ} \mathrm{C}$. The gaseous ions sampled by the capillary $( \pm 48 \mathrm{~V})$ were transmitted through a skimmer $( \pm 4 \mathrm{~V})$ and accumulated for $2-5 \mathrm{~s}$ in an rf hexapole $(600$ peak-to-peak voltage [Vp-p]). The ions were subsequently ejected from the hexapole and injected at \pm 2700 $\mathrm{V}$ into the bore of the superconducting magnet, decelerated, and introduced into the ion cell. Two flexible heating blankets placed around the portion of the vacuum tube that surrounds the ion cell controlled the temperature of the ion cell for the BIRD experiments. The typical base pressure for the instrument was $\sim 5 \times$ $10^{-10}$ mbar. Data acquisition was performed using the XMASS (version 5.0) software (Bruker, Billerica, MA). The time-domain signal consisted of the sum of 30 transients containing $128 \mathrm{~K}$ data points per transient.

\section{Results and Discussion}

\section{Influence of Solution Conditions on the Assembly of the Stx1 and Stx2 B Subunits}

To establish whether the structural homologies observed in their X-ray crystal structures translate to comparable thermodynamic stability in solution, we investigated the influence of subunit concentration, temperature, ionic strength, and $\mathrm{pH}$ on the assembly of the Stx1 and Stx2 B subunits in aqueous solution.

Influence of B subunit concentration. Nano-ES mass spectra were recorded in positive and negative ion modes for aqueous solutions of Stx1 B or Stx2 B subunits at concentrations ranging from 5 to $85 \mu \mathrm{M}$, with $25 \mathrm{mM}$ of ammonium acetate at $\mathrm{pH} 7$ and $25^{\circ} \mathrm{C}$ (Figures 1 and 2). Under the solution conditions investigated, only ions corresponding to the $\mathrm{B}_{5}$ homopentamer of Stx1 were observed in the mass spectra. No ions corresponding to monomers, dimers, trimers, or tetramers were detected in these experiments. In positive ion mode, the Stx1 B pentamer was observed predominantly as the protonated ion $\left(\mathrm{B}_{5}+n \mathrm{H}\right)^{n+} \equiv$ $\mathrm{B}_{5}{ }^{n+}$, where $n=12-14$ (Figure 1a), although small amounts of alkali metal ion adducts were observed at the lower subunit concentrations investigated (Figure 1b). In negative ion mode, the Stx1 B pentamer was observed almost exclusively as the deprotonated ion $\left(\mathrm{B}_{5}\right.$ $-n \mathrm{H})^{z-} \equiv \mathrm{B}_{5}^{z-}$ ions, where $z=12-14$ (Figure 1c). These data suggest that the Stx1 B subunit existed almost exclusively in its pentameric form under the solution conditions examined. Attempts to induce disassembly of the pentamer through dilution were unsuccessful. Dilution of the sample to subunit concentrations $<1 \mu \mathrm{M}$ led to a significant degradation of the signal-to-noise ratio $(\mathrm{S} / \mathrm{N})$ of the spectra, making it impossible to 
(a)
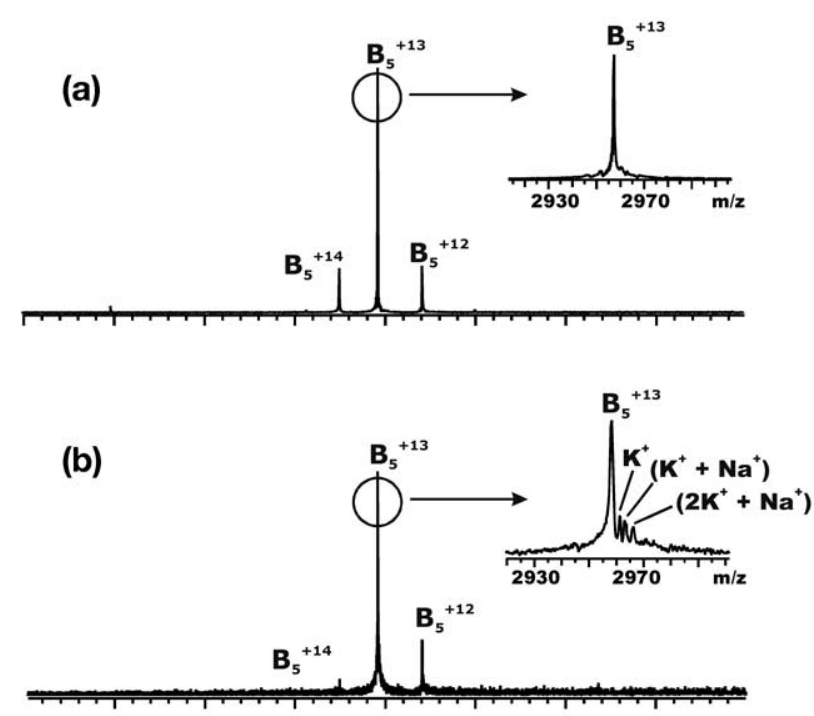

Figure 1. Nano-ES mass spectra of aqueous solutions of the Stx1 $B$ acquired in positive mode at a subunit concentration of (a) 85 $\mu \mathrm{M}$ and (b) $4 \mu \mathrm{M}$, and in the negative mode at (c) $25 \mu \mathrm{M}$. All solutions contained $25 \mathrm{mM}$ of ammonium acetate and were at $\mathrm{pH}$ 7 and $25{ }^{\circ} \mathrm{C}$.

positively identify any B subunit ions. Consequently, it was not possible to establish whether assembly of Stx1 $B$ into pentamers was reversible under these conditions.

In contrast to what we observed with the Stx1 B subunit, the assembly of Stx2 B subunit was found to be exquisitely sensitive to concentration. At the highest Stx2 B subunit concentrations investigated, $65 \mu \mathrm{M}$, the protonated $\mathrm{B}_{5}^{n+}$ ions, where $n=11-14$, constituted the major ions observed in positive ion mode. However, ions corresponding to dimer $\left(\mathrm{B}_{2}^{+7}\right)$, trimer $\left(\mathrm{B}_{3}^{+9}, \mathrm{~B}_{3}^{+10}\right)$, and tetramer $\left(\mathrm{B}_{4}^{+10}, \mathrm{~B}_{4}^{+11}\right)$ were also clearly evident, albeit at lower abundance (Figure 2a). Interestingly, ions corresponding to the homodecamer, $\mathrm{B}_{10}^{+19}$ and $\mathrm{B}_{10}^{+20}$, were also present in the spectra. The formation of the Stx2 B decamer has not, to our knowledge, been previously observed. Possibly, the decamer ions result from nonspecific dimerization of two pentamers during the nano-ES process. Several laboratories have previously shown that nonspecific protein complexes can form during the ES process [26, 27]. It has also been shown that the tendency for nonspecific binding is strongly dependent on analyte concentration, with higher con- centrations leading to more extensive nonspecific complexes [28, 29]. Although the possibility that the decamer was formed by nonspecific interactions can not be conclusively ruled out, it is, in our opinion, unlikely, given that there was no evidence of the corresponding Stx1 B decamer ions, despite the higher concentrations of Stx1 pentamer in the nano-ES solution. The present results suggest, therefore, that the decameric species observed for the Stx2 B subunit originated in solution.

Dilution of the Stx2 B subunit sample resulted in a decrease in the relative abundance of the pentamer, as well as the disappearance of the decamer, and a concomitant increase in the abundance of the smaller multimers and the appearance of $\mathrm{B}^{+4}$ and $\mathrm{B}^{+5}$ monomer ions (Figures $2 b, c)$. Mass spectra acquired in negative ion mode were found to resemble closely the spectra measured in the positive ion mode, both in terms of the ions present and their relative abundance (Figure $2 b, d$ ). It should be noted that the nano-ES mass spectra shown in Figure 2 were acquired after allowing the nano-ES
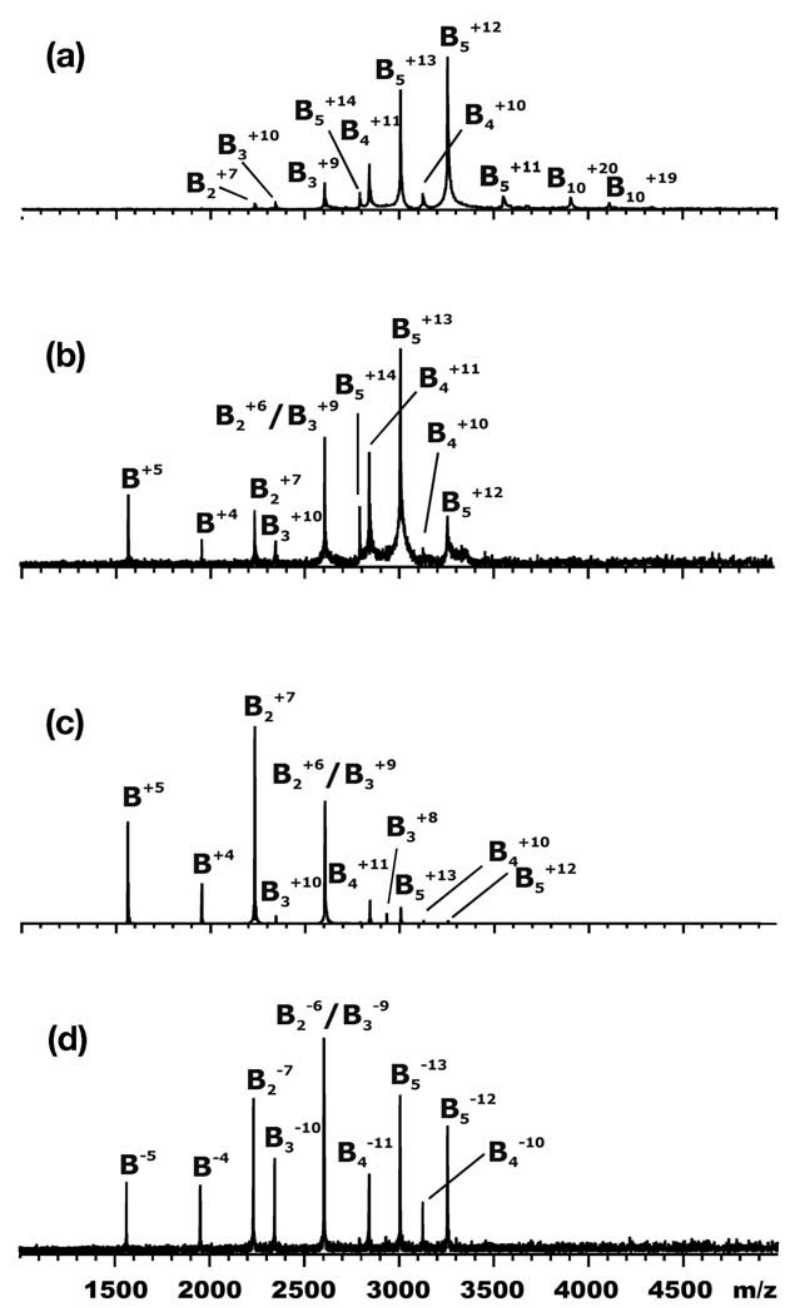

Figure 2. Nano-ES mass spectra of aqueous solutions of the Stx2 $\mathrm{B}$ acquired in positive ion mode at a subunit concentration of (a) $65 \mu \mathrm{M}$, (b) $48 \mu \mathrm{M}$, and (c) $25 \mu \mathrm{M}$ and in negative mode at (d) 48 $\mu \mathrm{M}$. All solutions contained $25 \mathrm{mM}$ of ammonium acetate and were at $\mathrm{pH} 7$ and $25^{\circ} \mathrm{C}$. 
solutions to stand for more than $10 \mathrm{~min}$ after diluting the stock solution. This was done to ensure an equilibrium distribution of the different oligomeric forms of the $\mathrm{B}$ subunits in the nano-ES solution. Mass spectra acquired at shorter times were found to exhibit a striking dependence on spray time. Shown in Figure 3 are mass spectra acquired in positive ion mode at different spray times (while continuously spraying the solution), immediately following the preparation of a 25 $\mu \mathrm{M}$ solution of the Stx2 B subunit with $10 \mathrm{mM}$ of ammonium acetate. The mass spectra acquired immediately after preparation of the nano-ES solution suffered from poor $\mathrm{S} / \mathrm{N}$. However, ions believed to correspond to $\mathrm{B}_{5}^{n+}$, at charge states of $n=11-13$, and the $\mathrm{B}^{+5}$ monomer were observed (Figure $3 a)$. The peaks corresponding to the $\mathrm{B}_{5}^{n+}$ ions are very broad and the ions are believed to be formed with a varying number of adducts. Because of limitations in the mass resolution achievable with the FT-ICR/MS used in the present work, the adducts could not be positively identified. However, several groups previously reported observing gaseous protein complex ions with extensive adducts, which they suggested to correspond to neutral or charged buffer species and alkali metal ions present in solution and, possibly, solvent molecules that were kinetically trapped within the complex [30-35]. In an effort to remove the adducts from the $B_{5}^{n+}$ ions, the ions were heated in the ion cell with blackbody radiation before detection. Shown in Figure 4 are mass spectra obtained for the $\mathrm{B}_{5}^{+10}$ and $\mathrm{B}_{5}^{+11}$ ions before and after heating the ions for $5 \mathrm{~s}$ at a cell temperature of $160^{\circ} \mathrm{C}$. It can be seen that there is little change in the width of the peaks, indicating that the adducts are kinetically quite stable. Consequently, it is unlikely that the adducts are solvent molecules or neutral buffer components, because these would be expected to readily dissociate from the protein ions in the heated ion cell [36]. With increasing spray duration, the relative abundance of the Stx2 B pentamer ions decreased and concomitantly, ions corresponding to monomer $\left(\mathrm{B}^{+5}\right.$ and $\left.\mathrm{B}^{+4}\right)$, dimer $\left(\mathrm{B}_{2}^{+6}\right.$ and $\left.\mathrm{B}_{2}^{+7}\right)$, trimer $\left(\mathrm{B}_{3}^{+9}\right.$ and $\left.\mathrm{B}_{3}^{+10}\right)$, and tetramer ions $\left(\mathrm{B}_{4}^{+10}\right.$ and $\mathrm{B}_{4}^{+11}$; Figures $\left.3 \mathrm{~b}, \mathrm{c}\right)$ appeared in the mass spectra. Interestingly, the longer spray times also resulted in a noticeable reduction in the abundance of adducts of the pentamer and smaller multimers. This phenomenon, which to our knowledge has not been previously described, was observed at all solution conditions investigated but was most noticeable at the lowest Stx2 B subunit concentration $(25 \mu \mathrm{M})$, where little pentamer is present at equilibrium. Although the origin of this phenomenon is not known, it may arise from changes in the conformation of the $\mathrm{B}$ subunits in solution, perhaps because of the lower ionic strength of the diluted sample solution. At a spray time of $\sim 10 \mathrm{~min}$, the major ions observed in the mass spectra corresponded to protonated monomer ions and smaller oligomer ions, with very little pentamer present (Figure 3d). Mass spectra recorded at longer spray times did not exhibit any further changes, indicating that an equilib-
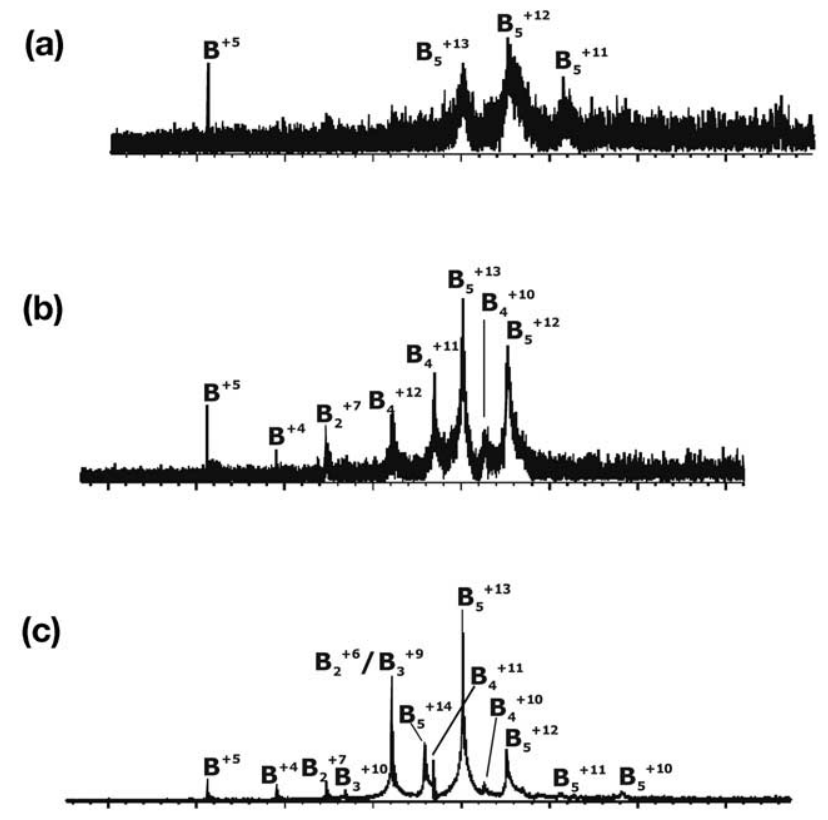

(d)

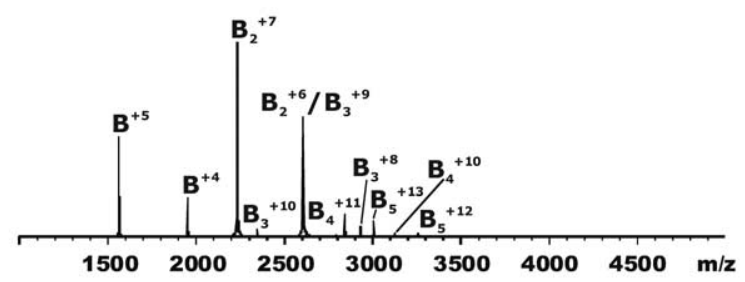

Figure 3. Nano-ES mass spectra of aqueous solutions of the Stx2 $\mathrm{B}(25 \mu \mathrm{M})$ in $10 \mathrm{mM}$ of ammonium acetate obtained in the positive mode (a) immediately after preparing the sample solution and after different spray time intervals of (b) $3 \mathrm{~min}$, (c) $6 \mathrm{~min}$, and (d) $10 \mathrm{~min}$. The solution contained $10 \mathrm{mM}$ ammonium acetate and was at $\mathrm{pH} 7$ and $25^{\circ} \mathrm{C}$.

rium distribution of the different forms of the B subunit was achieved after $\sim 10 \mathrm{~min}$.

The differences in the nano-ES mass spectra recorded for solutions of the Stx1 and Stx2 B subunits strongly suggest that the thermodynamic stability of the homopentamers differ, at least under the solution conditions investigated. However, when evaluating protein oligomerization by ES/MS, it is important to be vigilant against spectral artifacts arising from the ES process, such as nonspecific binding and gas-phase dissociation reactions in the ion source. It is possible that the spectral differences observed for the Stx 1 and Stx 2 B subunits originated from dissociation of the Stx2 B pentamer ions during sampling into the mass spectrometer. As described previously, the internal energy of gaseous ions sampled into the ion source of the mass spectrometer used for the present measurements is most significantly influenced by energetic collisions within the rf hexapole used to accumulate them [28]. Collisional heating during the accumulation event may induce dissociation of the $\mathrm{B}_{5}^{n+}$ ions and smaller multimers, if present. In a previous study, it was shown that the +9 to +11 ions of a $27 \mathrm{kDa}$ protein-trisaccharide complex had an effective 

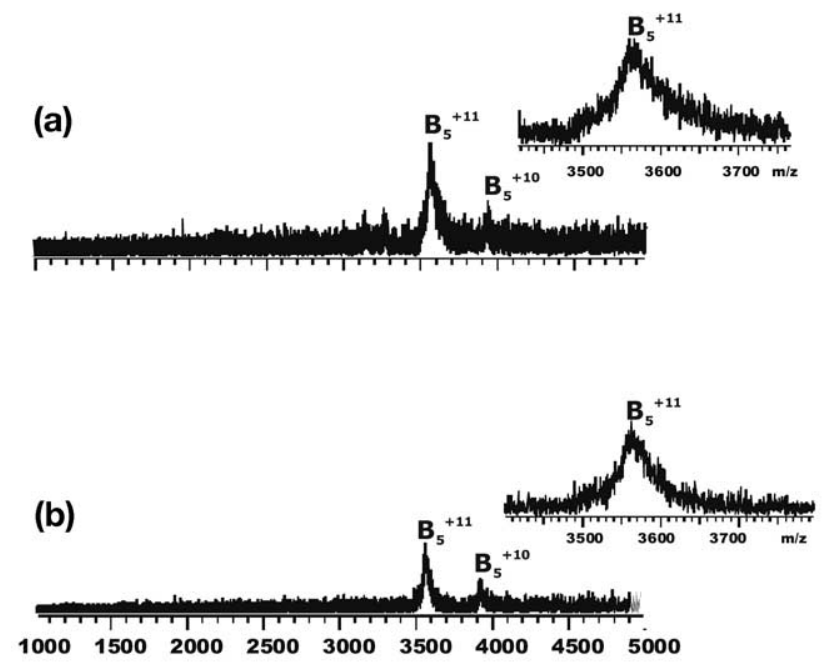

Figure 4. (a) Nano-ES spectrum acquired in positive ion mode for an aqueous solution of Stx2 B $(25 \mu \mathrm{M})$ and $10 \mathrm{mM}$ of ammonium acetate at $\mathrm{pH} 7$ and $25^{\circ} \mathrm{C}$; (b) BIRD snapshot mass spectrum obtained for the $\mathrm{St} \times 2 \mathrm{~B}_{5}^{+10}$ and $\mathrm{B}_{5}^{+11}$ ions after heating for $5 \mathrm{~s}$ at a cell temperature of $160^{\circ} \mathrm{C}$.

temperature of $\sim 140{ }^{\circ} \mathrm{C}$ in the hexapole region at accumulation times $\geq 2 \mathrm{~s}$ [28]. The $\mathrm{B}_{5}^{n+}$ ions investigated here are also expected to be collisionally heated in the hexapole, although because of their larger mass (39 $\mathrm{kDa})$, they may experience lower effective temperatures. To establish whether the Stx2 $\mathrm{B}_{5}^{n+}$ ions and smaller multimers, if present, undergo collision-induced dissociation in the source, the accumulation time was varied from 2 to $5 \mathrm{~s}$. Shown in Figure 5 are mass spectra acquired for a $65-\mu \mathrm{M}$ solution of the Stx2 B subunit with a hexapole accumulation time of 2 and $5 \mathrm{~s}$. It can be seen that there is no significant difference in the mass spectra recorded at different accumulation times, suggesting that gas-phase dissociation of the Stx2 $\mathrm{B}_{5}^{n+}$ ions in the source does not occur to any appreciable extent. However, possibly some of the $\mathrm{B}_{5}{ }^{n+}$ ions have lifetimes much shorter than the minimum sampling time $(\sim 2 \mathrm{~s})$ and dissociate in the source region.

To more convincingly show that gas-phase dissociation reactions do not contribute to the appearance of the Stx2 B subunit mass spectra, time-resolved BIRD experiments were performed on the protonated Stx $2 \mathrm{~B}_{5}^{+12}$ and $\mathrm{B}_{5}^{+13}$ ions at temperatures ranging from 120 to $180^{\circ} \mathrm{C}$. Illustrative BIRD spectra are shown in Figure 6a, c. It can be seen that the Stx2 $\mathrm{B}_{5}^{n+}$ ions dissociated preferentially by the loss of a single B subunit, which was ejected with a significant fraction of the total charge available. Such "asymmetric" dissociation is general for gaseous multiprotein complexes, independent of the number of subunits contained within the complex [22, 37, 38]. Dissociation of the Stx $2 \mathrm{~B}_{5}^{+12}$ ion proceeded exclusively by the loss of a monomer at the +4 charge state (eq 1):

$$
(\mathrm{Stx} 2) \mathrm{B}_{5}^{+12} \rightarrow \mathrm{B}^{+4}+\mathrm{B}_{4}^{+8}
$$
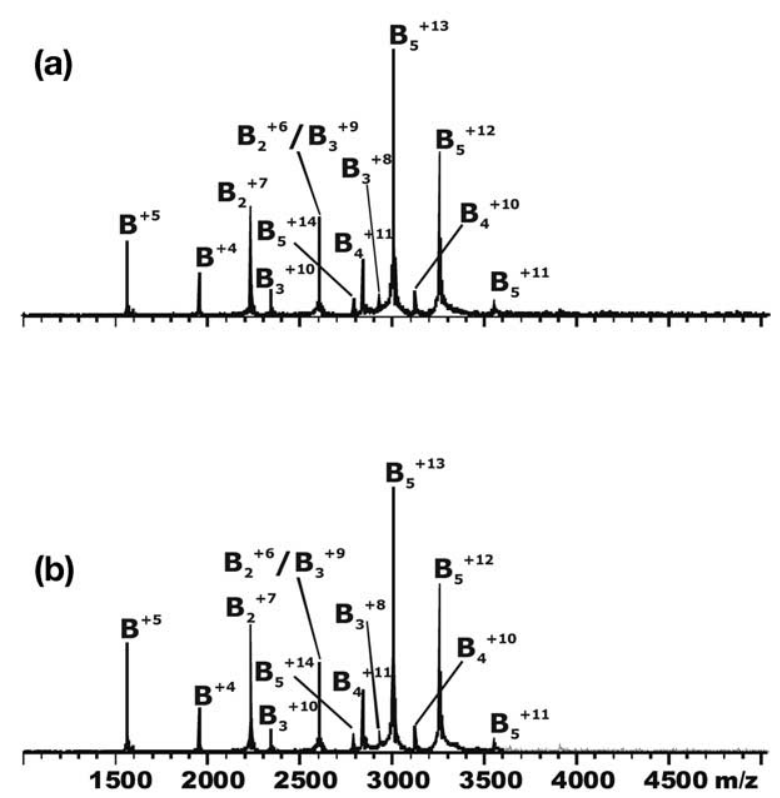

Figure 5. Nano-ES mass spectra acquired for an aqueous solution of Stx2 B $(65 \mu \mathrm{M})$ with a hexapole accumulation time of (a) $2 \mathrm{~s}$ and (b) $5 \mathrm{~s}$.

Dissociation of the Stx $2 \mathrm{~B}_{5}^{+13}$ proceeded preferentially by the loss of monomer at the +5 and +4 charge states (eqs 2a and b). However, a second, but minor dissociation pathway, resulted in the formation of dimers and trimers at charge states +6 and +7 , respectively (eq 2c):

$$
\begin{aligned}
& (\mathrm{Stx} 2) \mathrm{B}_{5}^{+13} \rightarrow \mathrm{B}^{+4}+\mathrm{B}_{4}^{+9} \\
& \rightarrow \mathrm{B}^{+5}+\mathrm{B}_{4}^{+8} \\
& \rightarrow \mathrm{B}_{2}^{+6}+\mathrm{B}_{3}^{+7}
\end{aligned}
$$

(a)

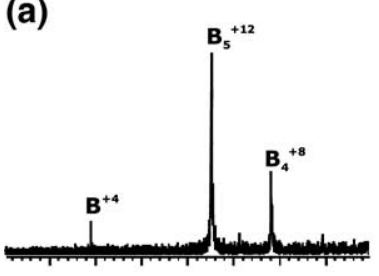

(b)

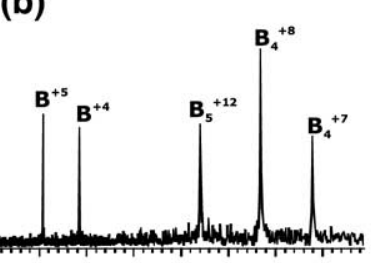

(c)

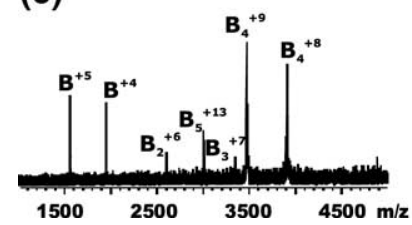

(d)

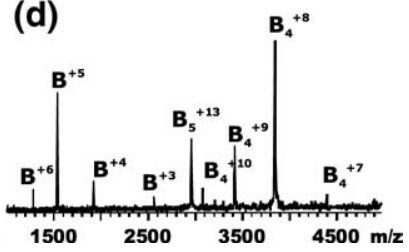

Figure 6. BIRD mass spectra of the protonated pentamer ions, Stx1 $B_{5}$ and Stx2 $B_{5}$, at charge states +12 and +13: (a) Stx2 $B_{5}^{12+}$ and (b) Stx $1 \mathrm{~B}_{5}^{12}+$ at a cell temperature of $170{ }^{\circ} \mathrm{C}$ and a reaction time $1.5 \mathrm{~s}$; (c) Stx2 $\mathrm{B}_{5}^{13+}$ and (d) Stx $1 \mathrm{~B}_{5}^{13+}$ at a cell temperature of $155^{\circ} \mathrm{C}$ and a reaction time $3 \mathrm{~s}$. 
BIRD measurements performed on the corresponding Stx1 $B_{5}$ ions were previously reported [22]. Illustrative spectra are shown in Figures $6 \mathrm{~b}$, $\mathrm{d}$ for comparison purposes. It can be seen that the dissociation pathways are quite similar, although charge enrichment of the ejected monomer is more pronounced in the case of the Stx1 $\mathrm{B}_{5}^{n+}$ ions. Although the monomer charge states observed in the BIRD spectra of the Stx $2 \mathrm{~B}_{5}^{n+}$ ions are consistent with the charge observed in the nano-ES mass spectra of the Stx2 B subunit (Figure 2), the tetramer ion charge states are not. More importantly, the abundant dimer and trimer ions observed in the nano-ES mass spectra are inconsistent with the BIRD results, in which the production of dimer and trimer ions represents a minor dissociation pathway. Based on the BIRD data, as well as the insensitivity of the nano-ES mass spectra to the source conditions, it is concluded that the monomer and small multimers observed in the spectra of the Stx2 B subunit originated from solution and not from gas-phase dissociation of the Stx $2 \mathrm{~B}_{5}^{n+}$ ions in the ion source.

The influence of subunit concentration on the relative abundance of the different multimeric forms of the Stx B subunits indicates that assembly into pentamer is fully reversible and that the different oligomeric forms coexist at equilibrium. It is important to note that because of anticipated differences in ionization efficiencies of the different oligomeric forms of the B subunit resulting from differences in their size and chemical properties (e.g., surface activity), the relative abundance of the subunit ions observed in the mass spectra likely does not reflect, quantitatively, their relative abundance in solution.

Influence of temperature. To assess the influence of temperature on the quaternary structure of the Stx B subunits, nano-ES mass spectra were measured for solutions of Stx1 B and Stx2 B subunits at solution temperatures ranging from 0 to $60{ }^{\circ} \mathrm{C}$ using a temperature-controlled nano-ES device developed in our laboratory. It should be noted that Robinson and coworkers have previously reported the design of a temperature-controlled nano-ES device and its application to the study of the assembly/disassembly of multimeric protein complexes by nano-ES/MS [39-41]. Over the range of temperatures investigated, assembly of Stx1 B subunit exhibited only a minor dependence on temperature. Shown in Figure $7 \mathrm{a}, \mathrm{b}$ are mass spectra acquired for a solution of $85 \mu \mathrm{M}$ Stx $1 \mathrm{~B}$ subunit at 2 and $58{ }^{\circ} \mathrm{C}$, respectively. The mass spectra measured at $2{ }^{\circ} \mathrm{C}$ are virtually indistinguishable from those acquired at 25 ${ }^{\circ} \mathrm{C}$ (Figure 1), with only $\mathrm{B}_{5}^{n+}$ ions, at $n=11-13$, observed. At $58{ }^{\circ} \mathrm{C}$, the Stx $1 \mathrm{~B}_{5}^{n+}$ ions represent the most abundant species present, although there was a noticeable shift in the charge state distribution to $n=12-15$ and a significant increase in the abundance of alkali metal ion adducts. In addition, Stx $1 \mathrm{~B}^{+4}$ and $\mathrm{B}^{+5}$ ions also were evident, albeit at low abundance, but there was no evidence of corresponding tetramer ions. The shift to higher charge states is consistent with the thermal-induced unfolding of subunits within the pentamer and suggests that disassembly of the pentamer is promoted by the loss of structure of the subunits. In contrast to the Stx1 B subunit, the quaternary structure of the Stx2 B subunit exhibited striking temperature dependence. Shown in Figure 7c, d are mass spectra acquired for a solution of $65 \mu \mathrm{M}$ Stx $2 \mathrm{~B}$ at 8 and $57^{\circ} \mathrm{C}$, respectively. At $8{ }^{\circ} \mathrm{C}$, the mass spectra revealed the presence of five different oligomeric states of Stx2 B subunit, monomer through pentamer. The charge states were similar to those observed at $25^{\circ} \mathrm{C}$ (Figure 2). At 57 ${ }^{\circ} \mathrm{C}$, the dominant Stx2 B subunit ions correspond to monomers, with small amounts of the other oligomeric forms. There was no significant difference in the charge states observed at low and high solution temperatures, which suggests that disassembly of the Stx2 B pentamer is not accompanied by significant unfolding of the subunits. The influence of solution temperature on the assembly of the Stx2 B subunit is more clearly seen in Figure $8 \mathrm{a}$, where the fractions of Stx2 B subunits in the different oligomeric states are plotted versus solution temperature. Figure $8 \mathrm{~b}$ illustrates the effect of solution ionic strength on the stability of the Stx2 B pentamer. It can be seen that at higher concentrations of ammonium acetate (34 mM versus $18 \mathrm{mM}$ ) the pentamer is more stable at solution temperatures higher than $35^{\circ} \mathrm{C}$. The influence of salt concentration on the stability of the Stx2 B pentamer highlights the importance of electrostatic interactions between subunits for their association into the pentameric complex.

Influence of $p H$. The influence of $\mathrm{pH}$ on the assembly of the Stx B subunits at $25^{\circ} \mathrm{C}$ was also investigated. Shown in Figure 9 are mass spectra acquired for solutions of the Stx1 $(65 \mu \mathrm{M})$ and Stx2 B $(65 \mu \mathrm{M})$ subunits at $\mathrm{pH} 4.0$. In the case of the Stx1 B subunit, acidification results in the appearance of monomer, dimer, trimer, and tetramer ions (Figure 9a). Similar behavior was observed for the Stx2 B subunit (Figure 9b). Interestingly, the differential stability of the Stx1 and Stx2 B subunits was
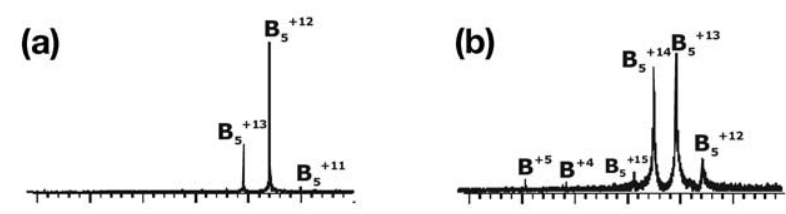

(c)

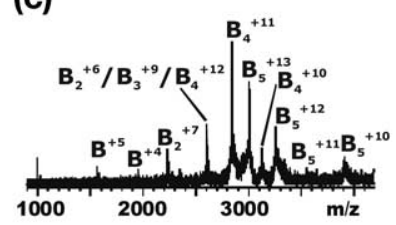

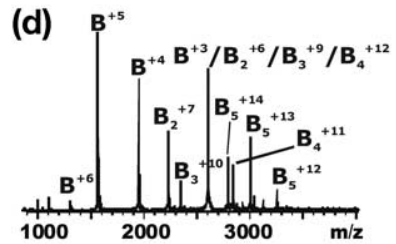

Figure 7. Nano-ES mass spectra of aqueous solutions of Stx1 B $(85 \mu \mathrm{M})$ at solution temperatures of $(\mathbf{a}) 2^{\circ} \mathrm{C}$ and (b) $58^{\circ} \mathrm{C}$, and of Stx2 B $(85 \mu \mathrm{M})$ at solution temperatures of (c) $8{ }^{\circ} \mathrm{C}$ and (d) $57^{\circ} \mathrm{C}$. 

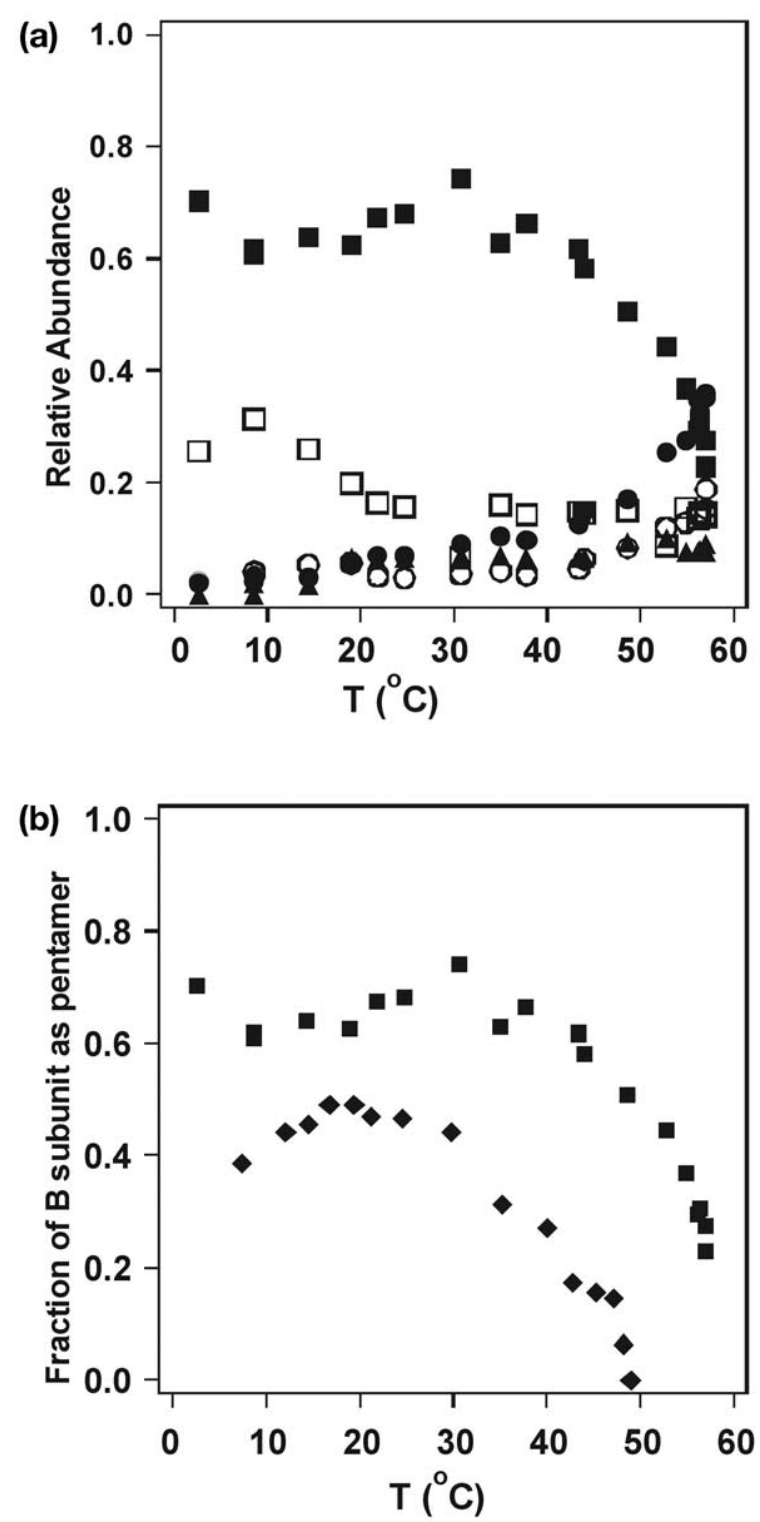

Figure 8. Influence of solution temperature on the assembly of the B subunit of Stx2 as monitored by nano-ES/MS. (a) The relative abundance of monomer (filled circle), dimer (open circle), trimer (filled triangle), tetramer (open square), and pentamer (filled square) determined for an aqueous solution of Stx2 B (85 $\mu \mathrm{M})$ and ammonium acetate $(34 \mathrm{mM})$ at different solution temperatures. (b) The fraction of Stx2 B subunit $(85 \mu \mathrm{M})$ present in solution as pentamer as a function of solution temperature at two different concentrations of ammonium acetate: $18 \mathrm{mM}$ (filled diamond) and $34 \mathrm{mM}$ (filled square).

less noticeable in acidified solutions. Under basic conditions ( $\mathrm{pH}$ 9) the stability of both the Stx1 and the Stx2 $B$ pentamers was similar to what we observed when the experiments were performed at $\mathrm{pH} 7$ (data not shown).

The acid-induced disassembly of the Stx1 pentamer may provide new insight into the origin of the loss of binding reported for the Stx1 B subunit- $\mathrm{P}^{\mathrm{k}}$ trisaccharide complex under acidic conditions. Using isothermal titration calorimetry, Toone and coworkers found that binding between the Stx1 B subunit and the $\mathrm{P}^{\mathrm{k}}$ trisac- charide is lost at $\mathrm{pH}<5$ [42]. It was proposed that protonation of a group of aspartate residues, believed to be important in the recognition of the $\mathrm{P}^{\mathrm{k}}$ trisaccharide, was responsible for the loss of binding. However, the present results suggest that disassembly of the pentamer may be responsible for the loss of binding under acidic conditions.

The similar stabilities of the pentamers of the B subunits of Stx 1 and Stx 2 observed under acidic conditions, together with sensitivity of Stx2 B subunit assembly to the presence of salt, suggest a possible role of destabilizing electrostatic interactions between an acidic residue, Asp70, located at its C-terminal end of Stx2 B and an acidic residue, Glu9, of the neighboring subunit as a likely cause of the differences in the assembly of the B subunits of Stx1 and Stx2. In this regard, the Stx1 B subunit has a basic amino acid, Arg69, at its C-terminal end. The increased protonation (neutralization) of the acidic residues at low $\mathrm{pH}$, as well as screening of electrostatic interactions at higher salt concentrations, is expected to eliminate or reduce the effects of the repulsive Asp70-Glu9 interaction, in agreement with the experimental observations. Of course, protonation of the acidic residues would also result in a reduction of the stabilizing electrostatic interactions (i.e., salt bridges) [43, 44]. Consequently, the overall stability of Stx2 B pentamer would be expected to decrease with decreasing $\mathrm{pH}$, which is consistent with our experimental observations.

On binding to their cell surface Gb3 receptors, Stx1 and $\mathrm{St} \times 2$ are believed to be internalized into endosomes, which then transport the toxins, via a unique Golgi-
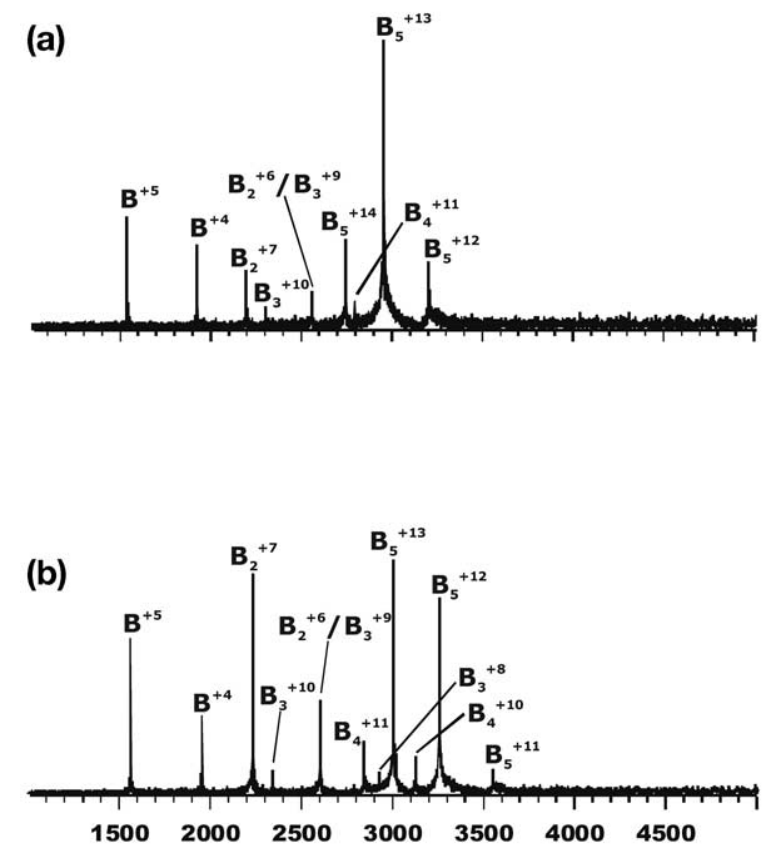

Figure 9. Nano-ES mass spectra of aqueous solutions of (a) Stx1 B $(65 \mu \mathrm{M})$ and (b) Stx2 B $(65 \mu \mathrm{M})$ with $25 \mathrm{mM}$ of ammonium acetate at $\mathrm{pH} 4$. 
directed bypass pathway, to their intracellular destination, the endoplasmic reticulum [45]. This unique trafficking pathway may prevent these holotoxins from being exposed to the degradative environment of the late endosome/prelysosome compartment. Acidification of the endosomal compartment apparently is required for these vesicles to access this bypass pathway [45]. Therefore, the reduced stability of the Stx1 and Stx2 B subunits at $\mathrm{pH} 4$, as observed in the nano-ES/MS experiments may be functionally important if disassembly of the holotoxins also is a necessary step in the cellular intoxication process.

\section{Thermal Stability of the Gaseous Stx $B_{5}^{\mathrm{n}+}$ Ions}

The aforementioned results suggest that, despite the structural similarities suggested by their X-ray crystal structures, the homopentamers of the Stx1 and Stx2 B subunits possess different thermodynamic stabilities in solution. It was also of interest to establish whether these differences in stability in solution are reflected in the gas phase. To our knowledge, a comparison between the thermal stability of structurally related multiprotein complexes in solution and in the gas phase has not been reported previously. It should be noted that direct measurement of the thermodynamic stability of multiprotein complexes in the gas phase is not possible because of the extremely low vapor pressure of proteins. Instead, the stability of protein complexes in the gas phase can only be assessed from measurements of their dissociation kinetics (for cleavage of the noncovalent intersubunit interactions). When performed under thermal conditions, the gas-phase kinetic measurements allow for the determination of the Arrhenius activation parameters for dissociation, which can be compared directly with the enthalpies and entropies of association determined in solution [46].

To evaluate the stability of the Stx $2 \mathrm{~B}_{5}^{n+}$ ions, Arrhenius activation parameters were determined from the temperature dependence of the dissociation kinetics established from time-resolved BIRD data acquired for the $\mathrm{B}_{5}^{+12}$ and $\mathrm{B}_{5}^{+13}$ ions. The thermal rate constant $(k)$ for the loss of a single subunit from a given $\mathrm{B}_{5}^{n+}$ ion was determined from a plot of the natural logarithm of the normalized abundance of the pentamer $\left(A_{\mathrm{B} 5}\right)$ versus reaction time:

$$
\ln \left(A_{B 5}\right)=-k t
$$

The normalized abundance was calculated using the expression:

$$
A_{B 5}=A_{B 5} /\left(A_{B 5}+A_{B 4}+A_{B 3}+A_{B 2}+A_{B}\right)
$$

where $A_{\mathrm{B} 4}, A_{\mathrm{B} 3}, A_{\mathrm{B} 2}$, and $A_{\mathrm{B}}$ correspond to the measured abundance of the tetramer, trimer, dimer, and monomer production ions, respectively. Shown in Figure 10 are the kinetic plots obtained for $\mathrm{B}_{5}^{+12}$ and $\mathrm{B}_{5}^{+13}$ ions at two temperatures. For comparison purposes, kinetic data measured in a previous study [22] for the corresponding Stx $1 \mathrm{~B}_{5}^{+\mathrm{n}}$ ions at similar temperatures are also shown. The kinetic plots obtained for the Stx $1 \mathrm{~B}_{5}^{+\mathrm{n}}$ ions are reasonably linear at the temperatures investigated, consistent with a single dominant structure for the $\mathrm{B}_{5}^{n+}$ ions. In contrast, the plots obtained for Stx 2 are nonlinear, with the rate of dissociation decreasing with reaction time.

There are a number of possible explanations for the nonlinearity of first-order kinetic plots [47]. Possibly, the $\mathrm{B}_{5}^{n+}$ ions of Stx 2 consist of multiple, noninterconverting structures with distinct dissociation rate constants. Alternatively, thermally induced changes in the conformation of the complex, leading to a kinetically more stable structure, may occur over the course of the reaction, and, thereby, alter the rate of dissociation. From the present measurements it is not possible to determine conclusively the origin of the kinetic effect. Nevertheless, from a comparison of the kinetic plots in Figure 10 , clearly, the $\mathrm{B}_{5}^{n+}$ ions of Stx 2 are kinetically more stable than those of Stx1, at least at the temperatures investigated.

The nonlinear kinetic plots obtained for the Stx2 B subunit complicated the determination of the dissociation rate constant. Estimates of the rate constants for dissociation of the most reactive ions were obtained by applying a linear least-squares fit to the initial or "fast" component of the kinetic plots. From the temperature dependence of the rate constants determined in this fashion, Arrhenius plots for the dissociation of the $\mathrm{B}_{5}^{n+}$ ions were constructed (Figure 11). Also shown are the Arrhenius plots for the corresponding Stx1 ions [22]. Despite the uncertainty associated with the rate constants for Stx2, the Arrhenius plots exhibit good linearity over the range of temperatures investigated. The Arrhenius activation energy $\left(E_{\mathrm{a}}\right)$ and preexponential factor $(A)$ were determined from the slope and $y$ intercept, respectively, of the plots and the values are listed in Table 1.

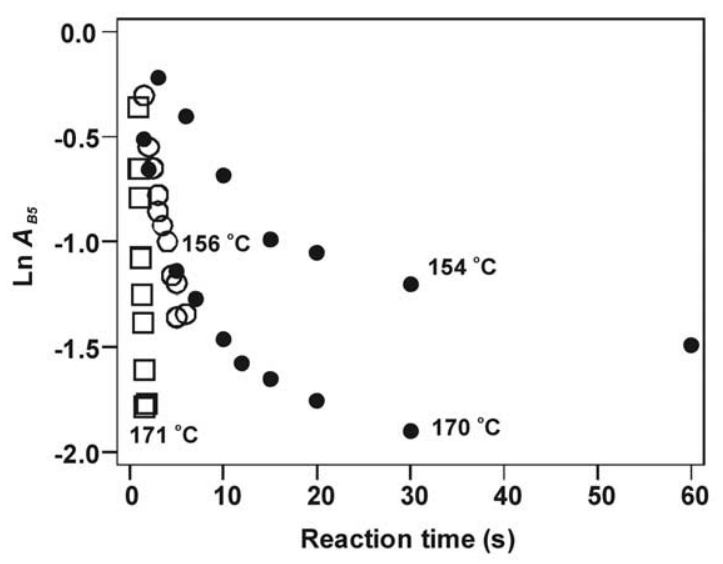

Figure 10. Plots of the natural logarithm of the normalized abundance of the protonated +12 ions Stx1 and Stx $2 B_{5}$ versus time at reaction temperatures 156 (open circle) and $171^{\circ} \mathrm{C}$ (open square) (Stx1 $\left.\mathrm{B}_{5}\right)$, and 154 and $170{ }^{\circ} \mathrm{C}$ (filled circle; Stx2 $\mathrm{B}_{5}$ ). 
It can be seen that, despite the differences in kinetic stability, the values of $E_{\mathrm{a}}$ for the $\mathrm{B}_{5}^{n+}$ ions of Stx1 and Stx2 are identical within experimental error, $52 \mathrm{kcal} / \mathrm{mol}(+12)$ and $46-47 \mathrm{kcal} / \mathrm{mol}(+13)$. The similarity in the $E_{\mathrm{a}}$ values determined at a given charge state may suggest that the ions are stabilized by similar intermolecular interactions, which is consistent with the similar intersubunit interactions suggested by an analysis of holotoxin crystal structures. It is possible, therefore, that the solution-specific interactions are preserved on transfer of the complex from solution to the gas phase by nano-ES. However, it also is possible that the complexes are stabilized, either wholly or in part, by nonspecific interactions that form during the nano-ES/desolvation. It has been previously shown that nonspecific intermolecular interactions can contribute significantly to the stability of noncovalent biomolecular complexes in the gas phase [48]. In an effort to establish whether any specific interactions are preserved in the gaseous complexes, our laboratory is currently investigating the thermal stability of gaseous $\mathrm{B}_{5}^{n+}$ ions composed of mutant Stx B subunits, in which amino acids believed to be involved in stabilizing the pentamers in solution have been selectively modified. Regardless of the nature of the interactions stabilizing the $\mathrm{B}_{5}^{n+}$ ions of the Stx 1 and Stx2 B subunits in the gas phase, the BIRD results clearly show that the relative energetic stability of multiprotein complexes in the gas phase do not necessarily correlate with the relative stability in solution.

\section{Conclusions}

Nano-ES and FT-ICR/MS were used to investigate the solution and gas-phase stability of the $B_{5}$ homopentamer of Stx1 and Stx2. Despite the structural similarities suggested by their respective X-ray crystal structures, oligomerization of the $\mathrm{B}$ subunits differs in

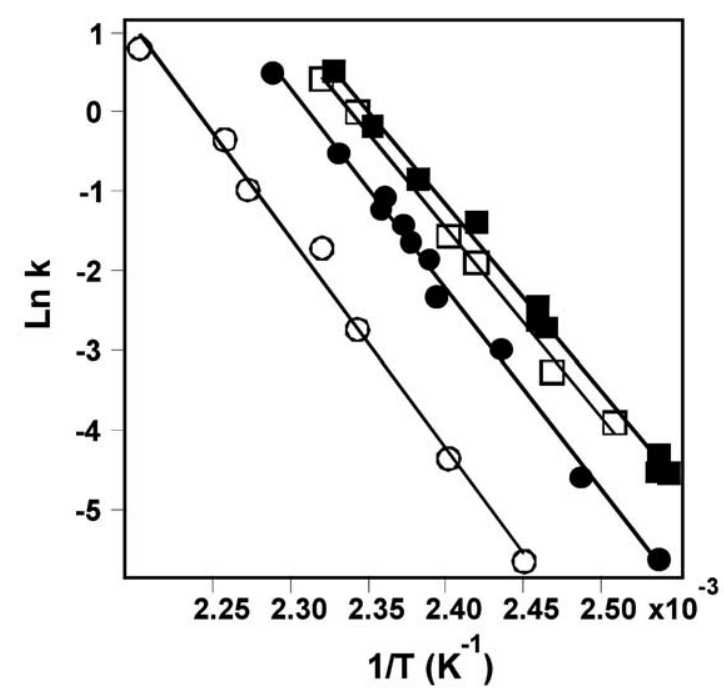

Figure 11. Arrhenius plots for the dissociation of the protonated gaseous pentamer ions: St $x 1 B_{5}^{+12}$ (filled circle), Stx $1 B_{5}^{+13}$ (filled square), Stx $2 B_{5}^{+12}$ (open circle), and St $\times 2 B_{5}^{+13}$ (open square).
Table 1. Arrhenius activation parameters for the dissociation of the protonated $B_{5}$ ions of the Stx 1 and Stx2 B subunits into monomers and tetramers: $\mathrm{B}_{5}{ }^{n+} \rightarrow \mathrm{B}^{x+}+\mathrm{B}_{4}{ }^{(n-x)+}$

\begin{tabular}{llll}
\hline Pentamer & Major products & $\mathrm{E}_{\mathrm{a}}(\mathrm{kcal} / \mathrm{mol})^{\mathrm{a}}$ & \multicolumn{1}{c}{$\mathrm{A}\left(\mathrm{s}^{-1}\right)^{\mathrm{a}}$} \\
\hline \hline Stx1 $\mathrm{B}_{5}{ }^{+12}$ & $\mathrm{~B}^{+4} / \mathrm{B}_{4}{ }^{+8}, \mathrm{~B}^{+5} / \mathrm{B}_{4}{ }^{+7}$ & $51.8 \pm 1.1^{\mathrm{b}}$ & $10^{26.2 \pm 0.6 \mathrm{~b}}$ \\
Stx2 $\mathrm{B}_{5}{ }^{+12}$ & $\mathrm{~B}^{+4} / \mathrm{B}_{4}^{+8}$ & $52.2 \pm 2.1$ & $10^{25.6 \pm 1.0}$ \\
Stx1 $\mathrm{B}_{5}^{+13}$ & $\mathrm{~B}^{+4} / \mathrm{B}_{4}{ }^{+9}, \mathrm{~B}^{+5} / \mathrm{B}_{4}{ }^{+8}$ & $46.2 \pm 1.1^{\mathrm{b}}$ & $10^{23.0 \pm 0.6 \mathrm{~b}}$ \\
Stx2 $\mathrm{B}_{5}{ }^{+13}$ & $\mathrm{~B}^{+4} / \mathrm{B}_{4}{ }^{+9}, \mathrm{~B}^{+5} / \mathrm{B}_{4}{ }^{+8}$ & $47.1 \pm 1.6$ & $10^{24.1 \pm 0.8}$ \\
\hline
\end{tabular}

${ }^{\mathrm{a}}$ Errors are $1 \mathrm{SD}$.

bValues taken from Ref. 22.

solution, at least under the conditions investigated. At subunit concentrations of 5-85 $\mu \mathrm{M}$ and temperatures ranging from 0 to $60^{\circ} \mathrm{C}$, the Stx $1 \mathrm{~B}$ subunit exists almost exclusively in its pentameric form at neutral $\mathrm{pH}$. Acidification was found to promote disassembly. In contrast, although the Stx2 B subunit forms abundant pentamer $(\sim 80 \%)$ at subunit concentrations of $\sim 65 \mu \mathrm{M}$, neutral $\mathrm{pH}$, ambient temperature and relatively high salt concentration, it dissociates into smaller oligomers and monomers when one or more of these parameters were altered. The lower thermodynamic stability of the B subunits of Stx2, compared with Stx1, is a significant finding because it may provide an explanation for the greater toxicity of Stx2 relative to Stx1. In an effort to establish whether a link between the stability of Stx B subunits and holotoxin toxicity exists, our laboratory has undertaken a comparative study of the stabilities of a number of mutant $B$ subunits and the toxicities of the corresponding mutant holotoxins.

Time-resolved thermal dissociation experiments performed using the BIRD technique on the gaseous pentameric complexes of the Stx1 and Stx2 B subunits, at the +12 and +13 charge states, revealed that their stability in the gas phase does not reflect their behavior in solution. At a given charge state, the dissociation $E_{\mathrm{a}}$ values for the $\mathrm{B}_{5}^{n+}$ ions of the Stx1 and Stx2 B subunits were indistinguishable, within experimental error. These results suggest similar or identical stabilizing intersubunit interactions, a result that is consistent with the X-ray crystal structures of the holotoxins. Kinetically, however, the $\mathrm{B}_{5}^{n+}$ ions of Stx2 B subunit were found to be more stable that those of the Stx1 B subunit. These results suggest that the relative stability of protein complexes in the gas phase may be a poor indicator of their relative stability in solution.

\section{Acknowledgments}

Financial support was provided by the Natural Sciences and Engineering Research Council of Canada and the Alberta Ingenuity Center for Carbohydrate Science. The authors thank the reviewers for their helpful comments and suggestions.

\section{References}

1. Karmali, M. A. Infection by Shiga Toxin-Producing Escherichia coli: An Overview. Mol. Biotechnol. 2004, 26, 117-122.

2. Nataro, J. P.; Kaper, J. B. Diarrheagenic Escherichia coli. Clin. Microbiol. Rev. 1998, 11, 142-201. 
3. Fraser, M. E.; Chernaia, M. M.; Kozlov, Y. V.; James, M. N. Crystal Structure of the Holotoxin From Shigella dysenteriae at 2.5 A Resolution. Nat. Struct. Biol. 1994, 1, 59-64.

4. Fraser, M. E.; Fujinaga, M.; Cherney, M. M.; Melton-Celsa, A. R.; Twiddy, E. M.; O'Brien, A. D.; James, M. N. Structure of Shiga Toxin Type 2 (Stx2) From Escherichia coli O157:H7. J. Biol. Chem. 2004, 279, 27511-27517.

5. Ling, H.; Boodhoo, A.; Hazes, B.; Cummings, M. D.; Armstrong, G. D.; Brunton, J. L.; Read, R. J. Structure of the Shiga-like Toxin I B-Pentamer Complexed With an Analogue of its Receptor Gb3. Biochemistry 1998, 37, 1777-1788.

6. Calderwood, S. B.; Auclair, F.; Donohue-Rolfe, A.; Keusch, G. T.; Mekalanos, J. J. Nucleotide Sequence of the Shiga-like Toxin Genes of Escherichia coli. Proc. Natl. Acad. Sci. U. S. A. 1987, 84, 4364-4368.

7. Strockbine, N. A.; Jackson, M. P.; Sung, L. M.; Holmes, R. K.; O'Brien, A. D. Cloning and Sequencing of the Genes for Shiga Toxin From Shigella dysenteriae Type 1. J. Bacteriol. 1988, 170, $1116-1122$.

8. Boodhoo, A.; Read, R. J.; Brunton, J. Crystallization and Preliminary X-Ray Crystallographic Analysis of Verotoxin-1 B-Subunit. J. Mol. Biol. 1991, 221, 729-731.

9. Richardson, J. M.; Evans, P. D.; Homans, S. W.; DonohueRolfe, A. Solution Structure of the Carbohydrate-Binding B-Subunit Homopentamer of Verotoxin VT-1 From E. coli. Nat. Struct. Biol. 1997, 4, 190-193.

10. Hashimoto, H.; Mizukoshi, K.; Nishi, M.; Kawakita, T.; Hasui, S.; Kato, Y.; Ueno, Y.; Takeya, R.; Okuda, N.; Takeda, T. Epidemic of Gastrointestinal Tract Infection Including Hemorrhagic Colitis Attributable to Shiga Toxin 1-Producing Escherichia coli $\mathrm{O} 118 \mathrm{H} 2$ at a Junior High School in Japan. Pediatrics 1999, 103, E2.

11. Head, S. C.; Petric, M.; Richardson, S.; Roscoe, M.; Karmali, M. A. Purification and Characterization of Verocytotoxin-2. Fems Microbiol. Lett. 1988, 51, 211-215.

12. Kleanthous, H.; Smith, H. R.; Scotland. S. M.; Gross, R. J.; Rowe, B.; Taylor, C. M.; Milford, D. V. Haemolytic Uraemic Syndromes in the British Isles, 1985-8: Association With Verocytotoxin Producing Escherichia coli. Part 2: Microbiological Aspects. Arch. Dis. Child 1990, 65,722-727.

13. Ostroff, S. M.; Tarr, P. I.; Neill, M. A.; Lewis, J. H.; HargrettBean, N.; Kobayashi, J. M. Toxin Genotypes and Plasmid Profiles as Determinants of Systemic Sequelae in Escherichia coli O157:H7 Infections. J. Infect. Dis. 1989, 160, 994-998.

14. Scotland, S. M.; Willshaw, G. A.; Smith, H. R.; Rowe, B. Properties of Strains of Escherichia coli Belonging to Serogroup O157 With Special Reference to Production of Vero Cytotoxins VT1 and VT2. Epidemiol. Infect. 1987, 99, 613-624.

15. Siegler, R. L.; Obrig, T. G.; Pysher, T. J.; Tesh, V. L.; Denkers, N. D.; Taylor, F. B. Response to Shiga Toxin 1 and 2 in a Baboon Model of Hemolytic Uremic Syndrome. Pediatr. Nephrol. 2003, 18, 92-96.

16. Tesh, V. L.; Burris, J. A.; Owens, J. W.; Gordon, V. M.; Wadolkowski, E. A.; O'Brien, A. D.; Samuel, J. E. Comparison of the Relative Toxicities of Shiga-Like Toxins Type I and Type II for Mice. Infect. Immunol. 1993, 61, 3392-3402.

17. Wadolkowski, E. A.; Sung, L. M.; Burris, J. A.; Samuel, J. E.; O'Brien, A. D. Acute Renal Tubular Necrosis and Death of Mice Orally Infected With Escherichia coli Strains That Produce Shiga-Like Toxin Type II. Infect. Immunol. 1990, 58, 3959-3965.

18. Head, S. C.; Karmali, M. A.; Lingwood, C. A. Preparation of VT1 and VT2 Hybrid Toxins From Their Purified Dissociated Subunits. Evidence for B Subunit Modulation of a Subunit Function. J. Biol. Chem. 1991, 266, 3617-3621.

19. Kitova E. N.; Kitov P. I.; Bundle D. R.; Klassen J. S. The Observation of Multivalent Complexes of Shiga-Like Toxin With Globotriaoside and the Determination of Their Stoichi- ometry by Nanoelectrospray Fourier-Transform Ion Cyclotron Resonance Mass Spectrometry. Glycobiology 2001, 11, 605-611.

20. Dunbar, R. C.; McMahon, T. B. Activation of Unimolecular Reactions by Ambient Blackbody Radiation. Science 1998, 279, 194-197.

21. Price, W. D.; Schnier, P. D.; Jockusch, R. A.; Strittmatter, E. F.; Williams, E. R. Unimolecular Reaction Kinetics in the HighPressure Limit Without Collisions. J. Am. Chem. Soc. 1996, 118, 10640-10644.

22. Felitsyn, N. F.; Kitova, E. N.; Klassen, J. S. Thermal Decomposition of a Gaseous Multiprotein Complex Studied by Blackbody Infrared Radiative Dissociation. Investigating the Origin of the Asymmetric Dissociation Behaviour. Anal. Chem. 2001, 73, 4647-4661.

23. Marcato, P.; Mulvey, G.; Read, R. J.; Vander, H. K.; Nation, P. N.; Armstrong, G. D. Immunoprophylactic Potential of Cloned Shiga Toxin 2 B Subunit. J. Infect. Dis. 2001, 183, 435-443.

24. Mulvey, G.; Vanmaele, R.; Mrazek, M.; Cahill, M.; Armstrong, G. D. Affinity Purification of Shiga-Like Toxin I and ShigaLike Toxin II. J. Microbiol. Methods 1998, 32, 247-252.

25. Daneshfar, R.; Kitova, E. N.; Klassen, J. S. Determination of Protein-Ligand Association Thermochemistry Using VariableTemperature Nanoelectrospray Mass Spectrometry. J. Am. Chem. Soc. 2004, 126, 4786-4787.

26. Versluis, C.; van der Staaij, A.; Stokvis, E.; Heck, A. J. R.; de Craene, B. Metastable Ion Formation and Disparate Charge Separation in the Gas-Phase Dissection of Protein Assemblies Studied by Orthogonal Time-of-Flight Mass Spectrometry. J. Am. Soc. Mass Spectrom. 2001, 12, 329-336.

27. Jurchen, J. C.; Williams, E. R. Origin of Asymmetric Charge Partitioning in the Dissociation of Gas-Phase Protein Homodimers. J. Am. Chem. Soc. 2003, 125, 2817-2826.

28. Wang, W. J.; Kitova, E. N.; Klassen, J. S. Influence of Solution and Gas Phase Processes on Protein-Carbohydrate Binding Affinities Determined by Nanoelectrospray Fourier Transform Ion Cyclotron Resonance Mass Spectrometry. Anal. Chem. 2003, 75, 4945-4955.

29. Wang, W. J.; Kitova, E. N.; Klassen, J. S. Nonspecific ProteinCarbohydrate Complexes Produced by Nanoelectrospray Ionization. Factors Influencing Their Formation and Stability. Anal. Chem. 2005, 77, 3060-3071.

30. Loo, J. A. Studying Noncovalent Protein Complexes by Electrospray Ionization Mass Spectrometry. Mass Spectrom. Rev. 1997, 16, 1-23.

31. Nettleton, E. J.; Sunde, M.; Lai, Z. H.; Kelly, J. W.; Dobson, C. M.; Robinson, C. V. Protein Subunit Interactions and Structural Integrity of Amyloidogenic Transthyretins: Evidence From Electrospray Mass Spectrometry. J. Mol. Biol. 1998, 281, 553-564.

32. Rostom, A. A.; Fucini, P.; Benjamin, D. R.; Juenemann, R.; Nierhaus, K. H.; Hartl, F. U.; Dobson, C. M.; Robinson, C. V. Detection and Selective Dissociation of Intact Ribosomes in a Mass Spectrometer. Proc. Nat. Acad. Sci. U. S. A. 2000, 97, 5185-5190.

33. Hanson, C. L.; Fucini, P.; Ilag, L. L.; Nierhaus, K. H.; Robinson, C. V. Dissociation of Intact Escherichia coli Ribosomes in a Mass Spectrometer. J. Biol. Chem. 2003, 278, 1259-1267.

34. Aquilina, J. A.; Robinson, C. V. Investigating Interactions of the Pentraxins Serum Amyloid P Component and C-Reactive Protein by Mass Spectrometry. Biochem. J. 2003, 375, 323-328.

35. Sobott, F.; McCammon, M. G.; Hernandez, H.; Robinson C. V. The Flight of Macromolecular Complexes in a Mass Spectrometer. Phil. Trans. R. Soc. B 2005, 363, 379-389.

36. Peschke, M.; Verkerk, U. H.; Kebarle, P. Features of the ESI Mechanism that Affect the Observation of Multiply Charged 
Noncovalent Protein Complexes and the Determination of the Association Constant by the Titration Method. J. Am. Soc. Mass Spectrom. 2004, 15, 1424-1434.

37. Light-Wahl, K. J.; Schwartz, B. L.; Smith, R. D. Observation of the Noncovalent Quaternary Associations of Proteins by Electrospray-Ionization Mass Spectrometry. J. Am. Chem. Soc. 1994, 116, 5271-5278.

38. Heck, A. J. R.; van den Heuvel, R. H. H. Investigation of Intact Protein Complexes by Mass Spectrometry. Mass Spectrom. Rev. 2004, 23, 368-389.

39. Fandrich, M.; Tito, M. A.; Leroux, M. R.; Rostom, A. A.; Hartl, F. U.; Dobson, C. M.; Robinson, C. V. Observation of the Noncovalent Assembly and Disassembly Pathways of the Chaperone Complex MtGimC by Mass Spectrometry. Proc. Nat. Acad. Sci. U. S. A. 2000, 97, 14151-14155.

40. Benesch, J. L. P.; Sobott, F.; Robinson, C. V. Thermal Dissociation of Multimeric Protein Complexes by Using Nanoelectrospray Mass Spectrometry. Anal. Chem. 2003, 75, 2208-2214.

41. Lentze, N. Aquilina, J. A. Lindbauer, M. Robinson, C. V. Narberhaus, F. Temperature and Concentration-Controlled Dynamics of Rhizobial Small Heat Shock Proteins. Eur. J. Biochem. 2004, 271, 2494-2503.
42. St. Hilaire, P. M.; Boyd, M. K.; Toone, E. J. Interaction of the Shiga-Like Toxin Type-1 B-Subunit With Its Carbohydrate Receptor. Biochemistry 1994, 33, 14452-14463.

43. Sinha, N.; Smith-Gill, S. J. Electrostatics in Protein Binding and Function. Curr. Protein Pept. Sci. 2002, 3, 601-614.

44. Yu, Y.; Monera, O. D.; Hodges, R. S.; Privalov, P. L. Ion Pairs Significantly Stabilize Coiled-Coils in the Absence of Electrolyte. J. Mol. Biol. 1996, 255, 367-372.

45. Natarajan, R.; Linstedt, A. D. A Cycling cis-Golgi Protein Mediates Endosome-to-Golgi Traffic. Mol. Biol. Cell 2004, 15, $4798-4806$

46. Kitova, E. N.; Bundle, D. R.; Klassen, J. S. Partitioning of Solvent Effects and Intrinsic Interactions in Biological Recognition. Angev. Chem. Int. Ed. 2004, 43, 4183-4186.

47. Wang, W.; Kitova, E. N.; Klassen, J. S. Structure and Stability of Protein-Carbohydrate Complexes in the Gas Phase. Origin of Nonspecific Binding. J. Am. Soc. Mass Spectrom. 2005, 16, 1583-1594.

48. Kitova, E. N.; Bundle, D. R.; Klassen, J. S. Thermal Dissociation of Protein-Oligosaccharide Complexes in the Gas Phase. Mapping the Intrinsic Intermolecular Interactions. J. Am. Chem. Soc. 2002, 124, 5902-5913. 